\title{
DIREITO, DEVIR NEGRO E CONFLITO ECOLÓGICO DISTRIBUTIVO
}

\section{RIGHT, BECOME BLACK AND DISTRIBUTING ECOLOGICAL CONFLICT}

\author{
Maria Cristina Vidotte Blanco Tárrega*
}

\begin{abstract}
Resumo: O escravismo colonial, como vetor de um processo de organização do capital e de construção de um sistema mundo, engendra uma perene desqualificação do Negro e o coloca às margens do mundo ocidental, transformando-o, no mundo globalizado contemporâneo, em sujeito de conflitos ecológicos distributivos, na luta por seus direitos. A partir disso e na perspectiva do direito, propõe-se refletir sobre a condição histórica do Negro como agente central e sujeito da luta e da resistência na conformação do capitalismo, para ressignificar o papel desses sujeitos de direito e de suas lutas nos conflitos originários do desenvolvimentismo globalizado. Faz-se uma abordagem analítica na literatura especializada sobre escravidão. Os conflitos ecológicos foram pensados a partir da ecologia política e o racismo foi abordado a partir da filosofia e da história críticas. Dos resultados, têm-se que o regime escravocrata foi central na construção do sistema mundo capitalista e que o direito estatal moderno serviu a instituição desse regime, negando a condição de sujeitos de direito aos escravizados. O direito moderno legitimou a hegemonia dos senhores de escravos e a inexistência de direitos aos cativos, mas criou as condições necessárias para a insurgência e o devir de resistência do ser escravizado, no âmbito de sua humanidade prorrogada. Essa resistência é perene diante do avanço das fronteiras do progresso, que invadem os territórios tradicionais ocupados pelos excluídos do direito no sistema capitalista, sobretudo os Negros. Instalam-se conflitos ecológicos distributivos e no âmbito deles as gentes resistem e os massacres acontecem. $\mathrm{O}$ racismo, como processo histórico continua.
\end{abstract}

Palavras-chave: Direito; Escravismo; Ecologia Política; Conflitos ecológicos distributivos; Comunidades negras.

\begin{abstract}
The colonial slavery, as a vector of a process of capital organization and the construction of a world system, engenders a perennial disqualification of the Black people and places it on the margins of the Western world, transforming it into a subject of ecological conflicts in the contemporary globalized world distributive, in the fight for their rights. From this and from the perspective of law, it is proposed to reflect on the historical condition of the Negro as a central agent and subject of struggle and resistance in the conformation of capitalism, to re-signify the role of these subjects of law and their struggles in the conflicts originated in the development. An analytical approach is made in the specialized literature on slavery. The ecological conflicts were thought from the political ecology and the racism was approached from the critical philosophy and history. From the results, it is shown that the slave system was central to the construction of the capitalist world system and that modern state law served the institution of this regime,
\end{abstract}

\footnotetext{
* Mestre e Doutora pela Pontifícia Universidade Católica de São Paulo. Professora Titular na Faculdade de Direito da Universidade Federal de Goiás e Professora na Universidade de Ribeirão Preto. Coordenadora do Núcleo Emergente Comunidades Tradicionais. CNPq Bolsista Produtividade em Pesquisa CNPq. Contato: mcvidotte@uol.com.br.
} 
Direito, devir negro e conflito ecológico distributivo

denying the condition of subjects of law to the enslaved. Modern law legitimized the hegemony of the slave owners and the lack of rights to the captives but created the necessary conditions for the insurgency and the becoming of resistance of the enslaved, within the scope of his extended humanity. This resistance is perennial in the face of the advance of the frontiers of progress, which invade the traditional territories occupied by those excluded from law in the capitalist system, especially the Blacks. Distributive ecological conflicts are set up and within them people resist and massacres happen. Racism as a historical process continues.

Keywords: Law; Slavery; Political Ecology; Distributive ecological conflicts; Black communities.

\section{INTRODUÇÃO}

A condição do afrodescendente subsaariano nas Américas, hoje, é consequência da violência histórica originária do escravismo moderno responsável pela organização do capital e fundante de um sistema mundo que, sem rupturas, chega à realidade contemporânea. Escravismo que é a base da história do afrodescendente neste continente pautada pela mercantilização e por esforços de desumanização dos sujeitos escravizados, o que os tornou, então, não sujeitos de direitos. E de sujeitos sem direitos, convertendo-os em sujeitos de resistência. Da condição originária de não ter direitos pela negação de subjetividade constróise uma trajetória que os constitui sujeitos de conflitos e lutas por direitos.

O escravismo colonial, como vetor de um processo de organização do capital e de construção de um sistema mundo, engendra uma perene desqualificação do Negro e o coloca às margens do mundo ocidental, transformando-o, no mundo globalizado contemporâneo, em sujeito de conflitos ecológicos distributivos, na luta por seus direitos.

O homem e a mulher escravizados foram convocados a reconfigurar suas vidas e a recriar modos de existência como resposta à própria continuidade do existir, e o fizeram a partir de uma integração com a natureza. Criaram modos de existir e estratégias de sobrevivência ligadas à terra e às suas potencialidade, que perduram até hoje. À medida que o capitalismo expande seus limites, avança sobre esses grupos e ameaça suas existências e a continuidade de seus modos de viver, de produzir e de reproduzir a própria cultura. Geram conflitos. Conflitos ocasionados por propostas desenvolvimentistas que se confrontam com formas não capitalistas e maneiras diversas de apropriação, uso e atribuição de significados ao território, vinculadas por interações ecossistêmicas engendradas como resposta de sobrevivência a esse sistema mundo capitalista excludente. Esse processo é sistêmico na acomodação das práxis econômica e ambiental e renova a resistência do Negro. 
Esse artigo propõe, no campo do direito, discutir e refletir sobre a condição histórica do Negro como agente central e sujeito da luta e da resistência na conformação do capitalismo, em razão do escravismo colonial, para ressignificar o papel desses sujeitos de direito e de suas lutas nos conflitos originários do desenvolvimentismo globalizado, pleno de contradições, de natureza estrutural. Faz-se uma abordagem analítica da literatura, fundada nos pensamentos de Jacob Gorender, em A Escravidão Reabilitada e de Achille Mbembe, A crítica da razão negra. Os conflitos ecológicos foram pensados a partir da ecologia política na expressão de autores com Grüner e Escobar. De igual importância para a análise, Lilia Moritz Schwartz, na obra Nem preto nem branco muito pelo contrário. Cor e raça na sociabilidade brasileira.

Dos resultados, têm-se que o regime escravocrata foi central na construção do sistema mundo capitalista e que o direito estatal moderno serviu a instituição desse regime, negando a condição de sujeitos de direito aos escravizados. A noção de sujeito de direito é uma construção histórica do liberalismo, que afere capacidade do sujeito a partir do potencial econômico de circulação de riquezas. Assim, o direito moderno legitimou a hegemonia dos senhores de escravos e a inexistência de direitos aos cativos, mas criou as condições necessárias para a insurgência e o devir de resistência do ser escravizado, no âmbito de sua humanidade prorrogada. Essa resistência é perene diante do avanço das fronteiras do progresso, que invadem os territórios tradicionais ocupados pelos excluídos do direito no sistema capitalista, sobretudo os Negros. Instalam-se conflitos ecológicos distributivos e no âmbito deles as gentes resistem e os massacres acontecem. O racismo, como processo histórico continua.

\section{O NEGRO DO NÃO DIREITO À RESISTÊNCIA NO ESCRAVISMO COLONIAL}

O direito no sistema escravocrata moderno coisifica os Negros escravizados. $\mathrm{Na}$ lei posta esses sujeitos são considerados bens. Coisas móveis, propriedade, mercadoria. O sistema mundo capitalista, instrumentalizado pelo estado nação e pelo direito estatal, nega direitos aos homens e mulheres postos em regime de trabalho escravo, não remunerado, fundado na violência e na coação. $O$ direito rege essas relações e garante a hegemonia dos senhores capitalistas, atribuindo-lhes direitos absolutos sobre as outras gentes, notadamente os cativos. O negar direitos, em razão de um processo escravocrata, afastava o direito estatal brasileiro, e latino americano como um todo, do ideal burguês da universalidade, da generalidade e da abstração, aproximando-o de um modelo de justiça em que se distinguem sujeitos e não sujeitos, favorecidos e privilegiados. 
Direito, devir negro e conflito ecológico distributivo

Como ponto de partida, observe-se que a noção de sujeito de direito é, antes de tudo, uma construção moderna liberal para afastar o modelo da medievalidade que distinguia os jurisdicionados por estamentos, e assim criar uma fórmula geral para estabelecer privilégios aos detentores do capital. Assim se põem os primados da igualdade e da liberdade ditames do modelo econômico capitalista referendados pela Revolução Francesa.

A noção de sujeito-pessoa elabora-se historicamente desde as primeiras incursões na ideia de indivíduo, mas é a modernidade que funda o indivíduo como núcleo de imputações e coloca o sujeito de direito como tema central das questões jurídicas. Com a consagração jurídica e política dos princípios da igualdade, da liberdade e da fraternidade que o sujeito torna-se o núcleo do direito. O liberalismo oferece as condições e as necessidades da noção de sujeito de direito-pessoa-indivíduo. Anteriormente no tempo, no mundo ocidental, os estatos e pertencimentos impedem a constituição de direitos dessa maneira, como também não há uma perspectiva antropocêntrica instituidora da pessoa sujeito de direito como centro de imputação de direitos. Há direitos personalíssimos, mas a pessoa não é o núcleo determinante da existência de direitos. Existe uma dimensão de justiça. $\mathrm{O}$ direito burguês propõe a universalização de normas para todos, instalando-se assim a necessidade de configuração de um sujeito individual e igual a todos. Por outro lado, a ideia de liberdade gera um protótipo de sujeito capaz da autodeterminação, de deliberar por si, por meio de contrato, capaz de dispor de sua esfera de interesses. Evidentemente, interesses econômicos. E posteriormente, a ideia de fraternidade conclama um sujeito a assumir-se numa relação com outro, ou ainda o coloca como terceiro, portanto, indivíduo. "O espírito burguês manifesta-se por meio de um individualismo anticorporativo que postula o cidadão como célula autônoma da humanidade, como centro de imputação de direitos subjetivos” (MARQUES, 2010, p.101).

Esses sujeitos, são dotados de personalidade com diferentes capacidades, mais ou menos reconhecidas, conforme seu potencial de riquezas. Os menos capacitados não são o alvo do direito. São as excepcionalidades. "O sujeito jurídico pressuposto é o homem adulto proprietário" (MARQUES, 2010, p. 104). É o sujeito que vai promover a circulação de riquezas numa perspectiva liberal.

É esse sujeito de direito no estado moderno- o homem com personalidade cuja capacidade se afere pela detenção de riquezas- que vai ser o objetivo último da normatividade. $\mathrm{O}$ homem dotado de capacidade econômica plena e de autodeterminação, 
numa perspectiva liberal. Nesse parâmetro da capacidade econômica que se estabelecem as referências de igualdade entre sujeitos e não sujeitos.

Ensina Decio Saes (2012, p.10) que a categoria de sujeito é a categoria central do direito capitalista e essencial à estruturação da economia capitalista. O sistema econômico capitalista, como os historicamente anteriores, implica na “[...] extração de trabalho excedente prestado por trabalhadores destituídos da propriedade dos meios de produção." (SAES, 2012, p.10). Apresenta, entretanto, uma diferença fundamental, a contratualização. $\mathrm{O}$ direito capitalista impõe a forma contratual à prestação de sobretrabalho e o sistema jurídico define os sujeitos de direito dessa relação contratual como "seres igualmente capazes de praticar atos de vontade, ou igualmente portadores de uma "vontade livre"." "Ou seja: na operação prática do direito, o sujeito moral atua como o complemento necessário do sujeito de direito" (SAES, 2012, p.10). Entendemos que a contratualização do trabalho não afasta a possibilidade de estabelecer-se um regime de trabalho fundado na violência, desde que afastada a condição de sujeito pessoa do ser humano escravizado, o que ocorreu no direito vigente.

Nesta perspectiva, consideramos nós, se organiza um sistema jurídico e uma normatividade que, sob o discurso da igualdade, distingue sujeitos e não sujeitos, garante a opressão de capitalistas sobre não capitalistas e legitima a escravidão.

Jacob Gorender, que considera o regime escravocrata de força de trabalho, não contratual, fundamental à formação do capitalismo, assevera que a formação social brasileira fincou suas raízes no modo de produção escravista colonial "[...] cujo funcionamento era assegurado pelo Estado e pelo regime jurídico”. (GORENDER, 2016, p.139) Nessa estrutura encontrava-se uma classe dominante colonial representada pelos senhores de escravos “encimada pela cúpula dos grandes plantadores" (GORENDER, 2016, p.139), que controlava o poder local e influenciava o poder regional e nacional. "Demais disso, a legislação emanada da Coroa para a colônia brasileira, possuía características especiais, adequadas à vigência do escravismo". (GORENDER, 2016, p.139). Acrescenta o autor que tivemos, no Brasil, o mais completo e típico estado escravista, o que foi garantido pelo direito. (GORENDER, 2016, p.140) "Em consequência, é também no século XIX que se cria, no Brasil, uma legislação organicamente abrangente e legitimadora da escravidão e das relações sociais dela decorrentes" (GORENDER, 2016, p.140).

O escravismo colonial foi determinante para construção da história da América, sobretudo pela resistência negra, fator importante na estruturação capitalista desses países, e isso se fortalece sobretudo a partir das muitas e diversas insurgências, revoltas, lutas, cujo ápice 
Direito, devir negro e conflito ecológico distributivo

é a revolução haitiana do final do século XVIII, que deu enorme contribuição e definiu os rumos do regime escravocrata nas Américas.

A literatura é inconteste sobre isso. O escravizado como agente subjetivo do processo do trabalho, sujeito resistente à violência fundante do sistema, fez o modelo capitalista e construiu as condições da abolição do sistema escravagista.

Eduardo Grüner em La obscuridad y las luces (2010), demonstra a impossibilidade de pensar a expansão do capitalismo sem o papel decisivo da escravidão para o seu desenvolvimento, sobretudo na intensificação das relações entre Europa, África e Américas. No Brasil, a importância do Negro na formação econômica e cultural do Brasil é apontada sobremaneira por Ordep Serra, em Olhos Negros do Brasil e por Jacob Gorender em Escravidão Reabilitada e em Escravismo Colonial.

A resistência negra teve papel fundamental no contexto escravista e abolicionista. Segundo Gorender, a coisificação social, caracteriza a escravidão, mas não importa em coisificação subjetiva do homem posto na condição de escravo. A pessoa do ser escravizado não é anulada, embora ferida e humilhada. "A sua humanidade intrínseca pode ser negada pelos seus proprietários, que deles extraem trabalho não remunerado; no entanto, não é inteiramente apagada, pelo menos num plano puramente ontológico" (MBEMBE, 2014, p.90). E a resistência à violação do ser é fator determinante para a preservação da subjetividade. "A resistência fazia parte intrínseca da adaptação, era necessidade incessante para o escravo, como o ar que respirava. Só assim impedia que a coisificação social do seu ser, imposta pelo modo de produção, se convertesse em coisificação subjetiva" (GORENDER, 2016, p.520)

O espaço do Negro é um espaço perene de ressignificações fundadas na resistência. Mbembe afirma ser próprio dessa humanidade prorrogada diante da negação da humanidade enfrentada pelos escravizados modernos “[...] anunciar um desejo radical, insubmersível e vindouro, de liberdade ou de vingança, principalmente quando tal humanidade não passa pela abdicação radical do sujeito.”(MBEMBE, 2014, p.91) Apesar do esforço jurídico de coisificação e da crueldade e degradação, os escravizados resistem como ser humano. "Pela sua mera existência, a comunidade de escravos não deixa de rasgar o véu da hipocrisia e da mentira que as sociedades esclavagistas" (MBEMBE, 2014, p.91).

Tanto o escravizado acomodado como o insurgente tiveram um papel histórico relevante na realização da resistência e, em nenhuma hipótese, se há de aceitar a existência de uma relação sem tensões entre senhor e escravo, assim como não se pode pensar em pactos nos termos característicos das relações contratuais entre eles. Aí não há contrato social. Há violência 
fundante e resistência.

De acordo com Gorender "Se o trabalho no capitalismo é contratual, o trabalho escravo tem sua origem na violência nua ou legalizada e não carece de sanções contratuais (GORENDER, 2016, p.48). Assim, também a violência praticada contra o escravizado caracteriza o sistema escravista. (GORENDER, 2016, p.49) O direito serve de instrumento de opressão mantendo, no caso escravista americano, características estamentais, ao negar a pretendida e nunca alcançada, talvez em nenhuma parte do mundo, os ideais de universalidade e generalidade, que seriam as características fundamentais e inafastáveis do direito burguês (mesmo porque o sistema mundo capitalista a que serve o direito burguês não permitiria) .

Isso coloca a pessoa resistente e ou insurgente numa condição determinante das relações capitalistas. O escravizado é, portanto, o agente subjetivo do processo de trabalho, segundo Gorender. Esse autor explica que sendo a relação fundada na violência, coativa, ela não é contratual e exige um custo maior de vigilância, como limite imposto pelos escravizados à rentabilidade do modo de produção escravista colonial.

Precisamente porque não podia ser contratual, pois se apoiava na coação, o trabalho escravo exigia o mais alto custo de vigilância- calculado como coeficiente do custo total-, dentre os tipos de trabalho baseados em relações antagônicas de exploração. O custo de vigilância se convertia em limite imposto pelos escravos à rentabilidade do modo de produção escravista colonial, nisso se manifestando sua influência como atores históricos efetivos. $\mathrm{O}$ custo de vigilância era um falso gasto de produção, ressarcido por uma parcela do excedente ou subproduto, o que comumente só vinha a ser factível em situações de preço de monopólio e de lucro de monopólio (GORENDER, 2016, pp.53 e 54).

Assim, na resistência se faz presente a influência desses sujeitos como atores históricos efetivos (GORENDER, 2016, p.53). "O escravo é o agente subjetivo do processo de trabalho e não um capital fixo, como tem sido classificado correntemente" (GORENDER, 2016, 54).

Atribuindo ao Negro uma humanidade prorrogada, Mbembe (2014, p.90) reforça a sua posição e a sua importância como ator histórico. Coloca o escravismo e o Negro- sinônimo de escravo e de homem-mercadoria- no centro da formação capitalista do mundo moderno, vendo-o como núcleo do processo no sistema de plantação brasileiro, caribenho e estadunidense. (MBEMBE, 2014, p. 88 e 89). O que o autor denomina de "complexo esclavagista atlântico" terá sido um canal expresso para a constituição do capitalismo moderno, produzindo um mundo muito diferente do que qualquer outra sociedade escravista pré-colonial houvera produzido. 
Direito, devir negro e conflito ecológico distributivo

Entretanto, há na literatura uma narrativa histórica que distorce o modelo escravocrata no Brasil, suavizando lhe os contornos, com clara intencionalidade de negar a importância do escravismo na formação da economia e da cultura modernas e assim desmanchar os rastros dessa instituição capitalista que foi a escravidão e dos homens e mulheres, protagonistas desse processo cruel construtor da aclamada democracia brasileira.

É imperativa a reconstrução histórica do escravismo para compreender o racismo e as injustiças sociais contemporâneos. Segundo Schwarcz (2012, p.116) na história estão as respostas para tentar explicar (e talvez vencer, digo eu) o racismo brasileiro já incapaz de se esconder na imagem da democracia racial, mas que ainda oculta as raízes de sua originalidade e reiteração permanente. "Se o mito deixou de ser oficial, está internalizado" Podemos encontrar seus rastros no campo histórico cuja característica indestrutível é uma estrutura jurídica de dominação e ocultamentos, estamental, na qual escravos e senhores ocupam posições de assujeitados, os primeiros e privilegiados, os segundos. Situação contra a qual se insurgem os escravizados e em favor de sua preservação reagem os senhores; essa postura reacionária é referendada pelo direito. $\mathrm{O}$ direito por seus diversos mecanismos e fontes preserva a hegemonia dos detentores do capital e dos poderosos, contrariamente aos direitos das gentes, notadamente dos trabalhadores cativos.

O direito brasileiro, mais especificamente o direito penal brasileiro dá claros indicativos da naturalização da diferença de tratamento entre sujeitos privilegiados e desfavorecidos. E a denominada "fonte doutrinária" (cuja intenção é inegavelmente doutrinar, recorrendo a argumentos de autoridade), representada por respeitados estudiosos, associa à ideia de raça às diferenças resultantes de fatores políticos e históricos. Schwarcz (2012, p.20) explica que vários autores- e são vários - que adotaram a ideia de raça vinculada ao darwinismo racial focado nos atributos externos e fenotípicos definidores da moralidade de um povo, procuraram fundamentar as diferenças na ordem da natureza. A autora cita Nina Rodrigues, grande expressão do pensamento brasileiro do final do século XIX, adepto das teorias raciais darwinistas, que "vê na criminalidade mestiça uma particularidade nacional" (SCHWARCZ, 2012, p.22) "O suposto era o da "desigualdade" e portanto, da necessidade de criação de códigos penais distintos, que permitissem estabelecer responsabilidades atenuadas" (SCHWARCZ, 2012, p.22). Acrescenta ainda, a autora, que segundo Rodrigues a "aplicação da lei deveria ser condicionada aos diferentes estágios de civilização e dimensionada pelo estudo das raças existentes no Brasil" garantindo-se sempre a impunidade. (SCHWARCZ, 2012, p.24). 
Até os dias atuais o preconceito originário dessa condição jurídica de inferioridade do ser humano escravizado e de seus descendentes é camuflado na sociedade e tem consequências na participação do Negro na vida social. Vencer o preconceito depende da revisão histórica do processo escravocrata a partir de muitas abordagens e da ampla difusão dos resultados desse trabalho em níveis educacionais distintos.

Essa revisão histórica há de se dar por múltiplos enfoques que se consorciem formando teias de compreensão, caso contrário os estudos ficarão reféns do pensamento tradicional e conservador sobre o tema.

Nessa ordem de reflexões, Eduardo Grüner (2010, p.99) considera imprescindível que a escravidão seja pensada como conceito, como instituição, como relação de poder, como configuração ideológica, como cultura, como discurso filosófico e científico, tendo em vista que ela provoca uma cisão entre brancos e não brancos, no mundo colonizado contemporâneo. A escravidão moderna, concorda o autor, foi fator determinante da criação de um sistema mundo moderno com sua lógica capitalista de desenvolvimento e expansão, baseada na racionalidade instrumental, no estado-nação e consequente nacionalismo, nas percepções racializadas da identidade, entre outros. Essa estrutura permanece. É a base do que se conhece hoje como globalização (GRÜNER, 2010, pp.142-143). O escravismo afro-americano foi determinante na criação desse sistema. Afirma Grüner que por razões econômicas e "raciais", os setores sociais mais explorados e empobrecidos pertencem a etnias não brancas e aos territórios historicamente submetidos ao processo de colonização. A geopolítica registra uma divisão não apenas territorial, mas notadamente cromática- brancos e não brancos (GRÜNER, 2010, p.144).

O que se vive hoje é a continuidade do mesmo sistema mundo capitalista estruturado a partir do escravismo colonial. A abolição não gera efetiva ruptura. Grüner (2010) denuncia que o marco dessa continuidade consiste em que o mundo inteiro e muito tipicamente o centro do mundo (fazendo aí uma alusão à queda do muro em 1989) levanta sempre novos muros para impedir o acesso aos de "certas cores" à terra prometida dos brancos. E quando os de "certas cores" conseguem ter acesso a ela, são submetidos a novas formas de escravidão. Isso desmente as formas ideológicas da fluidez globalizada, desmente também a falácia das democracias contemporâneas. Isso explica a perene violência contra os afrodescendentes subsaarianos nas Américas e o constante surgimento de novos conflitos ecológicos distributivos. 
Direito, devir negro e conflito ecológico distributivo

\section{CONFLITOS DISTRIBUTIVOS}

A noção de conflitos distributivos, mais precisamente conflitos ecológicos distributivos surge no campo da ecologia política cujas origens se encontram na preocupação com os impactos do modelo de desenvolvimento sobre a natureza e os povos pobres que vivem integrados a ela com conhecimentos fundados nessa comunhão, e a consequente destruição desse existir e da natureza, praticados nos último séculos em todo o mundo. Dada a condição em que os afrodescendentes participam da vida social, e como isso se dá historicamente, grande parte desses grupos vivem integrados à natureza com modos peculiares de viver, com saberes e fazeres próprios. Acabam mais uma vez sendo sujeitos da resistência. Sujeitos dos conflitos sobre os quais a ecologia política se debruça.

As origens da ecologia política, segundo Martínez-Allier (2004) e Arturo Escobar (1999), precursores desses estudos, estão na década de 60, na interlocução da ecologia cultural e humana com a antropologia ecológica e nos postulados da economia política, enfatizando a antropologia ecológica. Essa corrente da antropologia norteia-se pelo estudo das adaptações humanas locais a ecossistemas específicos, partindo do conflito social que estabelece "[...] la inexistência de instrucionais biológicas en los humanos sobre el uso exosomático de la energía y los materiales, razón por la cual esta disciplina estudia los determinantes físicos, biológicos y sociales del "metabolismo social" (MARTÍNEZ-ALLIER, 2004, p. 102). Jouvenel, politólogo e economista francês, precursor da economia ecológica usa a expressão pela primeira vez em 1957 e identifica múltiplas formas de relacionamento entre as estruturas sociais e o uso da natureza, noção fundamental para a ecologia política.

Na década de 80, segundo Martínez-Allier (2004) iniciam-se estudos rurais sobre as relações entre as estruturas sociais e meio ambiente, incluindo divisão de classes, de gênero, ingressos e poder, relatados por Eric Wolf. Assim, começam a surgir os conflitos ecológicos distributivos como campo específico de investigação.

O estudo dos conflitos ecológicos distributivos, como conflitos acerca do uso dos recursos naturais e da contaminação, é uma das vertentes da ecologia política. Distribuição, para fim de análise dos conflitos, se entende como "[...] los patrones sociales, espaciales y temporales de acceso a los beneficios obtenibles de los recursos naturales y a los servicios proporcionados por el ambiente como un sistema de soporte de la vida" (MARTÍNEZ-ALLIER, 2004a, p. 104). Isso implica, segundo Enrique Leff (2003) que a distribuição ecológica de conta das externalidades ambientais. Os 
movimentos sociais que surgem desses conflitos revelam assimetrias sociais, espaciais e temporais na utilização dos recursos e serviços ambientais, o que equivale à diminuição e à contaminação dos recursos naturais. Segundo os economistas ecológicos esses conflitos são êxitos na desterritorialização social e a transferência de custos ("éxitos en el desplazamiento social o traslado de los costes"). Os conflitos significam o sucesso da proposta desenvolvimentista sobre os grupos tradicionais e importam em custos que serão considerados na financeirização da natureza, sobretudo da terra. Para os economistas ortodoxos tratam-se de "externalidades" ou "falhas de mercado", que segundo (MARTÍNEZ-ALLIER, 2004a) é uma forma de camuflar a função econômica perversa deles.

Dentre as mais recorrentes espécies de conflitos apontados pela literatura especializada, encontram-se os, conflitos com mineração, com extração de petróleo, a degradação e erosão do solo, cultivos de madeira como se fossem florestas, a biopirataria, os gerados em defesa de manguezais contra indústria camaroneira, os conflitos pela água e pela sua mercantilização, por locais pela pesca, conflitos sobre o transporte, sobre traslado de materiais e energia, sobre resíduos e contaminação, uso de materiais tóxicos, segurança dos consumidores e cidadãos, exportação de resíduos tóxicos, sólidos o líquidos, contaminação transfronteriça. (MARTINEZ-ALLIER, 2004). No aspecto da disputa de poder, a Ecologia Política, segundo Allier tem por primeiro foco o poder como capacidade de impor uma decisão sobre os outros e na sequência o poder como a possibilidade de procedimento para impor um método de decisão de conflito, como o estabelecimento de uma linguagem única que triunfe e exclua outras linguagens de valoração, para julgar o conflito.

Os conflitos ecológicos revelam sujeitos de resistência que influenciam a história e por outro lado interferem no capitalismo pois implicam em custos, considerados sobretudo na especulação financeira com a terra e com os produtos dela originários, como as commodities minerais ou agrícolas. Entre esses sujeitos, destacam-se os grupos oriundos do regime escravocrata, tanto no Brasil como em outros países da América Latina. Mesmo nos países que não adotaram tal regime, como o Canadá, o problema do enfrentamento dos afrodescendentes com os projetos capitalistas de cunho desenvolvimentista persiste. Nesses países, grupos originários e evadidos do escravismo colonial se estabeleceram em locais então não alcançados pelos empreendimentos capitalistas. Com o avanço das fronteiras do desenvolvimento passaram a ter problemas idênticos e a representar a resistência. Segundo Van Dyk, no Canadá, o esforço incessante 
Direito, devir negro e conflito ecológico distributivo

dos subsaarianos contra o preconceito do branco, as terras inférteis e as más perspectivas econômicas caracterizaram a presença negra e impactaram a cultura na Nova Escócia, sendo isso visível até hoje, constituindo os maiores grupos minoritários ostensivos naquela província (VAN DYK, 2017).

Paulo E. Guimarães e Juan D. Pérez Cebada no texto denominado "O passado e o presente nos conflitos ambientais na indústria mineira e metalúrgica” (..) afirmam que embora esses conflitos não sejam considerados como conflitos de classe ou daí originários, aferem o poder na sociedade, notadamente na contraposição das comunidades, das elites locais e nacionais e de outros agentes responsáveis por projetos que constituam ameaças ao meio ambiente. Afirmam os autores (...) que os projetos industriais e de mineração afetam, com frequência a zona rural, trazendo o empobrecimento, a proletarização e a injustiça ambiental perene, "não são cobertas pela forma de compensação privilegiada pelo liberalismo: a indemnização pecuniária atribuída a título individual pela pessoa ou entidade responsabilizada através duma decisão judicial." Os povos oprimidos foram sempre, segundo os autores, chamados de irracionais, ignorantes e antiprogressistas contra o que reagem apoiados por grupos ambientalistas. (...) "A extensão sucessiva das fronteiras da ação industrial explicaria assim, por hipótese, surtos reativos que precedem a acomodação social a novos ambientes." A disseminação dos conflitos é sintoma de uma crise ambiental mundial. (...) Essa crise implicará em custos.

A existência desses conflitos, segundo os autores, geram reações diferentes. Implicam um custo político para o Estado e financeiro para as empresas. Afirmam, rememorando Dukes (2004) e O’Leary (2003): “Por outro lado, um conhecimento político emergente gestionário deste tipo crises nas universidades e em ramos especializados dos governos visam criar condições para impedir a sua emergência ou minorar os custos deste tipo de conflitos para as empresas e para o poder político."

Complementando a análise dos conflitos Arturo Escobar (2018) inclui o aspecto cultural nos três temas de maior relevância que estão interrelacionados nos conflitos distributivos- o econômico, o ecológico e a diferença cultural. "Os conflitos de distribuição cultural surgem da diferença entre o poder efetivo associado com as práticas os significados particulares da cultura" (ESCOBAR, 2018, p.75). Culturas cujas diferenças alteram a definição da vida social com os seus mais diversos componentes. "O poder habita no significado e os significados são um recurso fundamental do poder social; 
as lutas pelo significado são assim centrais para a estruturação do social e do mundo físico por si mesmo" (ESCOBAR, 2018, p.75). Segundo o autor, o aspecto cultural cada vez mais integra uma tríade com o econômico e o ecológico na manifestação do conflito.

No âmbito das comunidades afrodescendentes, os conflitos originários da disputa por territórios permeado por seus significados culturais próprios e nele incluídos os aspectos econômicos, ecológico, tem se intensificado, sobretudo com a expansão da fronteira agrícola e com o avanço do neoextrativismo, da mineração, notadamente no Brasil. O Relatório dos Conflitos no Campo, produzido pela Comissão Pastoral da Terra, aponta significativo aumento de áreas de conflito e de assassinatos, nos últimos anos (CPT, 2018).

As disputas por territórios decorrem de propostas agressivas de exploração de recursos e por desenvolvimento agrícola em confronto com formas não capitalistas de apropriação, uso e atribuição de significados ao território, vinculadas por interações com a natureza. Os conflitos têm caráter sistêmico na acomodação da práxis econômica e ambiental, e dão origem a grupos e modos de resistência à desigualdade por eles gerada. A produção neoliberal afeta o modo de vida local, provoca a disputa pela apropriação formal do conhecimento tradicional, gera a desterritorialização e o racismo ecológico. As coletividades que vivem no campo resistem e, dessa maneira, instala-se o conflito. Conflito que redundará em ganho financeiro para o capital especulativo.

Sauer ao tratar da demanda global considera a influência dos conflitos e a importância estratégica dos sujeitos do campo. Afirma a existência de um movimento de financeirização voltado aos setores alimentar e agrícola, gerando uma volatilidade dos preços, fruto das especulações o que afeta diretamente a demanda global -preços, disputas e conflitospor terras e por recursos naturais, promovendo a expansão das fronteiras agrícolas. "Esta é a conexão e a atualização da questão agrária, dando importância à terra, para além da histórica concentração da estrutura fundiária, reeditando a importância estratégica dos sujeitos do campo.” (SAUER, 2016, p.80). Não raras vezes essas terras são ocupadas por comunidades tradicionais, muitas delas por grupos de pessoas afrodescendentes, como os quilombolas.

Carlos Walter Porto-Gonçalves, em estudo sobre a luta pela terra na América Latina afirma que em toda a história da humanidade não houve um período de 50 anos com a destruição de tantas comunidades étnicas e camponesas. (PORTO-GONÇALVES, 2018, p.54). 
Direito, devir negro e conflito ecológico distributivo

\section{A VIOLÊNCIA CONTRAO NEGRO PERDURA}

A escravidão no Brasil é a mais duradoura do continente. E dela restaram as resistências que nunca desapareceram do cenário brasileiro, sejam elas no campo cultural, no religioso ou nos quilombos. Os traços da resistência à escravização perduram no Negro brasileiro, nos quilombos e nos diversos territórios constituídos por força da exclusão e da resistência. Os parcos reconhecimentos de direitos desses povos é consequência dessa força perene de luta e perseverança. Os quilombos, assim como os terreiros, as terras de santos, são a resistência viva.

As lutas das gentes insurrecionadas contra o estado nação e seu direito excludente trouxe no plano político algumas mudanças. O século XX, na América o horizonte constitucional e com ele os horizontes político e jurídico dos povos e com eles os afrodescendentes muda. A começar pela Constituição Mexicana que proibiu a escravidão, em 1917. As constituições latino-americanas mais recentes incorporam a questão do afrodescendente. Assim a Constituição da República Federativa do Brasil, que covardemente deixou para o Ato de Disposições Transitórias. Outras avançam mais como a da Colômbia, da Nicarágua e do Equador ${ }^{1}$. A Constituição da Colômbia de 1991 tratou, no art. 7, da diversidade "étnica e cultural da nação", estabelecendo o prazo de cinco anos para edição de lei conferindo às comunidades negras que tenham ocupado terras baldias nas zonas rurais ribeirinhas dos rios da Bacia do Pacífico, de acordo com as suas práticas tradicionais de produção, o direito à propriedade coletiva sobre as áreas que a referida lei demarcar (art. 55 dispositivo transitório), o que foi regulamentado pelas Leis no 70/93 e 397/1997.

A Constituição da Nicarágua de 1987 garantiu às denominadas comunidades da costa atlântica o direito a "preservar e desenvolver sua identidade cultural na unidade nacional, dotar-se de suas próprias formas de organização social e administrar seus assuntos locais conforme suas tradições", reconhecendo-lhes as formas comunais de propriedade das terras, uso, gozo e desfrute das águas e bosques destas terras ( art. 89). Garantiu, ainda, o desenvolvimento de sua cultura e afirmando que seus valores enriquecem a cultura nacional, constituindo dever do Estado a criação de programas especiais para o exercício de seus direitos de livre expressão e "preservação de suas línguas, arte e cultura" (art. 90). Também assegurou-se lhes o procedimento de titulação das terras por lei infraconstitucional, em 2003.

A Constituição do Equador de 1988 reconheceu aos povos Negros ou afro 
equatorianos o direito de conservar "a propriedade imprescritível das terras comunitárias, que serão inalienáveis, não-embargáveis e indivisíveis, ressalvada a faculdade do Estado para declarar sua utilidade pública", mantendo-se a posse das terras e obtendo-se sua "adjudicação gratuita, conforme a lei" (arts. 84, itens 2 e 3 c/ art. 85). Nesse país, a ordem infraconstitucional garantiu direitos aos afroequatorianos. A Lei dos Direitos Coletivos dos Povos Negros ou Afroequatorianos, de 2006, assegurou a preservação das expressões culturais e artísticas dos povos Negros (art. 3), o reconhecimento de direitos econômicos, sociais, culturais e políticos (art. 9), a conservação da biodiversidade em benefício coletivo (art. 11), a caça e pesca para subsistência com prioridade ante o aproveitamento comercial e industrial (art. 12), os direitos sobre recursos genéticos e filogenéticos (art. 14), a consulta sobre planos e programas de prospecção e exploração de recursos naturais que possam afetar referidas comunidades ambiental ou culturalmente (art.15), a garantia do fortalecimento e organização, em áreas urbanas ou rurais, dos sistemas e práticas de medicina natural tradicional (art. 18) e o respeito de formas próprias de organização e integração social afro equatorianas, tais como os palenques, comunas, comunidades urbanas e rurais, organizações de base e demais formas associativas que se determinem (art. 24).

A Constituição Equatoriana de 2008 trouxe uma série de direitos coletivos aos povos afro equatorianos (assim como aos indígenas, aos montubios, às comunas), entre os quais a não discriminação étnica ou cultural, a propriedade imprescritível das terras comunitárias, nos termos da Constituição anterior. Garantiu ainda a manutenção da posse de suas terras e territórios ancestrais e a adjudicação gratuita, a participação no uso, usufruto, administração e conservação dos recursos renováveis que se achem em suas terras, a consulta prévia, livre e informada, de caráter obrigatório, dentro de prazo razoável, sobre planos e programas de prospecção, exploração e comercialização de recursos não renováveis localizados em suas terras, a não translação de suas terras ancestrais, a participação na definição das políticas públicas a elas concernentes, bem como no desenho e decisão das prioridades nos planos e projetos do Estado, consulta antes da adoção de medida legislativa que possa afetar qualquer de seus direitos coletivos. Além disto, garantem-se a esses povos, no art. 58, os direitos coletivos estabelecidos em lei, pactos, convênios, declarações e demais instrumentos internacionais de direitos humanos" e a possibilidade de constituir circunscrições territoriais para a preservação de sua cultura, além das comunas como organização territorial (art. 60). 
Direito, devir negro e conflito ecológico distributivo

O Brasil tratou da questão quilombola, diretamente, depois da promulgação da Constituição de 1988, no artigo 68 do Ato das Disposições Constitucionais Transitórias (ADCT), e nos artigos 215 e 216 do próprio texto. O assunto foi regulamentado em Constituições Estaduais que reconhecem aos remanescentes dos quilombos a propriedade de suas terras. Assim as Constituições do Pará (Art. 232), de Mato Grosso (Art. 251 e 33 do ADCT), da Bahia (Art. 51), do Maranhão (Art. 229 do ADCT) e de Goiás (Art. 16 do ADCT).

Ainda que a conferência de direitos promova avanços, há que se considerar que nas constituições, as comunidades afrodescendentes ou foram tratadas como sobras de um sistema de exploração ou como patrimônio cultural e histórico, como resquícios de um passado perdido. Quando se fala em propriedade coletiva, isso na Constituição Federal, restringe-se a garantia dos direitos dos quilombos à noção civilista de propriedade da terra.

Os afrodescendentes, no plano de suas experiências, da ressignificação histórica, não conhecem condição de existência jurídica no plano de igualdades; o direito continua lhes sendo estamental, nas condições de preservação de um sistema mundo capitalista constituído a partir do escravismo colonial. O constitucionalismo democrático significa importante avanço nesse sentido, mas o fato de afrodescendentes constarem do discurso normativo não resulta igualdade com os brancos. Não implica que tenham acesso à terra prometida aos brancos; nas relações mediadas institucionalmente, sobretudo no discurso do judiciário e nas política públicas, sejam afirmados e reconhecidos como sujeitos de direito e tenham possibilidade de existência coletiva conforme sua auto-atribuição e plena capacidade de realizá-la, nos seus muitos aspectos.

Isso pode ser observado nas várias frentes de conflito enfrentadas por essas comunidades. Com relação ao reconhecimento estatal, notadamente com relação ao Incra. A Terra de direitos fez uma análise em 2016 segundo a qual em 5 anos o orçamento para regularização dos territórios quilombolas caiu em 97\%. Também analisa dados de certificação/titulação concluindo que nesse ritmo seriam mais de 900 anos para que todas as comunidades já certificadas recebessem seus títulos de propriedade. O próprio INCRA, no relatório disponibilizado na Internet informa que entre 2005 e 2017 foram conferidos 116 títulos apenas. Num contexto em que a propriedade privada tem uma função econômica, por excelência a consequência é a vulnerabilidade dos quilombolas e o acirramento dos conflitos, 
pois a terra continua em disputa e o território pode ser afetado por isso. Nesse sentido haverá um aumento do valor especulativo da terra.

Com isso, nas relações sociais vemos a violência contra os quilombolas aumentar. Segundo o Caderno de Conflitos da Comissão Pastoral da Terra houve, no Brasil 90 ocorrências de áreas de conflitos quilombolas em 2017, 99 em 2016.

Em 2017, registraram-se 22 assassinatos de quilombolas, em um número absoluto de 71 assassinatos por conflitos no campo. Em 2016, 7 quilombolas foram mortos de um total de 61. Em 2015, 1 quilombola de um total de 50 assassinatos. Há um crescimento da violência no campo, sendo muito mais expressivo contra quilombolas.

As razões apontadas, em regra, são empreendimentos - pequenas centrais hidrelétricas, MG, SP, PA, GO), especulação imobiliária, expansão da fronteira agrícola- o que caracteriza como conflito ecológico distributivo.

Referendando essas informações, a publicação "Racismo e Violência contra Quilombos no Brasil”, organizada pela Coordenação Nacional de Articulação das Comunidades Negras e Rurais Quilombolas e Terra de Direitos (2018) afirma que número de assassinatos de quilombolas no país cresceu 350\% em um ano, sendo que entre 2008 e 2017 ocorreram 29 assassinatos de quilombolas na região Nordeste, região há significativo número de projetos desenvolvimentistas, o que é indicado como possível causa. (2018)

Como agravante há a ocorrência de chacinas e de violência e tortura contra as mulheres. Em 2017, foram registrados dois casos de chacina - no Quilombo de Iúna, em Lençóis, na Bahia e no Quilombo Lagoa do Algodão, em Carneiros, Alagoas. A violência contra mulheres mostra na maioria dos casos a morte se deu com uso de arma branca, sendo utilizados métodos de tortura. Nessa pesquisa sobre violência verificou-se que o maior número das situações de ameaça se deu em razão de conflitos por território. (2018)

\section{CONSIDERAÇÕES FINAIS}

Os conflitos ecológicos distributivos são hoje uma grande ameaça aos grupos afrodescendentes subsaarianos, na continuidade de seus modos de viver, de produzir e de reproduzir a própria cultura. Modos esses que representam a resistência do Negro à assimilação pelo modelo desenvolvimentista e de mercado. Resistência que foi fator determinante para o fim da escravidão legal. Resistência que perdura até hoje, diante das desigualdades e da violência sofrida.

Os projetos geradores dos conflitos, invadem os espaços de vida dos povos 
Direito, devir negro e conflito ecológico distributivo

tradicionais, dos pobres, e destroem o patrimônio cultural; servem sobremaneira à especulação imobiliária e a desterritorialização das gentes. Tais conflitos são originários do avanço do capitalismo e dão continuidade a um sistema de inferiorização do Negro cujas raízes encontram-se no escravismo colonial, responsável, no entendimento dos autores apresentados, pela construção do sistema mundo que conhecemos. Um sistema mundo capitalista que hoje se alimenta do conflito, -na expansão dos megaprojetos sobre, entre outras, as terras de preto, - e da resistência a ele, pelas gentes que padecem na luta contra a especulação imobiliária e o desapossamento.

Os projetos desenvolvimentistas se confrontam com formas não capitalistas e conflitam com diferenças culturais que interferem na definição da vida social com todos os seus elementos, inclusive os transcendentais. Arranham as culturas e suas determinações normativas e suas maneiras diversas de apropriação, uso e atribuição de significados ao território, vinculadas por interações ecossistêmicas. Esses conflitos têm se manifestado em toda a América Latina, cuja economia originária do escravismo colonial, que lhe foi nuclear, integra o sistema mundo capitalista com caráter sistêmico na acomodação das práxis econômica e ambiental fomentando a resistência à desigualdade.

É preciso encontrar maneiras de enfrentamento desses conflitos característicos do neoliberalismo, ocorrentes no momento em que o capital se coloca com autonomia acima de tudo e de todos. É necessário buscar meios de combater o modelo capitalista e sua ideologia de crescimento exponencial que atinge a todos e pereniza o racismo ambiental.

O neoliberalismo eterniza o racismo inventando com escravismo para servir o sistema mundo. Tornamo-nos a cada dia mais intensamente vítimas e algozes desse racismo.

Concluindo com Mbembe, “o Negro e a raça nunca foram congelados”. Fazem parte de um encadeamento de coisas, por si nunca acabadas. "Produto de uma máquina social e técnica indissociável do capitalismo, da sua emergência e globalização, esse nome foi inventado para significar exclusão, embrutecimento, e degradação, ou seja, um limite sempre conjurado e abominado (MBEMBE, 2014, p.19).

\section{REFERÊNCIAS}

ALIMONDA, H.; TORO PEREZ, C.; MARTIN, F. Ecologia política latino-americana. Buenos Aires: CLACSO, 2018.

ALVARADO, G. et al. Gestión ambiental y conflicto social en América Latina, Buenos Aires: CLACSO, 2008. 
AMIN, S.; HOUTART, F. Mundialização das Resistências: O estado das lutas 2003. São Paulo, Cortez, 2003.

BARRICK GOLD CORPORATION. Barrick's Compliance Hotline. Disponível em https://secure.ethicspoint.com/domain/media/en/gui/41012/index.html (acesso em 2701-2016). 20/10/2018.

Code of Business Conduct and Ethics, rev. October 30, 2015 acesso em

CAMBAZA, V. A terra no contexto do desenvolvimento da indústria mineira: pressões e conflitos em torno dos duats. In: BRITO, L. et al., Desafios para Moçambique. Maputo, IESE, 2010, p.217-227.

COMISSÃO PASTORAL DA TERRA. Caderno de Conflitos 2017. Goiania: CPT, 2018.

CONAQ. Coordenação Nacional de Articulação das Comunidades Negras e Rurais Quilombolas e TERRA DE DIREITOS. Racismo e Violência contra Quilombos no Brasil, 2018. Disponível em www.terradedireitos.org. Acesso em 30/09/2018.

COUMANS, C. (2002), Placer Dome Case Study: Marcopper Mines. Disponível em http://miningwatch.ca/. Acesso 27/01/2018.

DELGADO RAMOS, G. C. (coord.) Ecologia Politica de la Minería en América Latina: Aspectos socioeconómicos, legales y ambientales de la mega minería. Mexico, UNAM. 2010.

DUKES, E. F. What We Know About Environmental Conflict Resolution: An Analysis Based on Research. In: Conflict Resolution Quarterly, vol. 22, 2004, n. 1-2, pp. 191220.

EJOLT. Barrick Gold Corporation. In: Environmental Justice Atlas. Disponível em http://ejatlas.org/company/barrick-gold-corporation. Acesso 27/09/2018.

ESCOBAR, A. Ecologia Politica de la globalidad e la diferencia. In: ALIMONDA, H. La naturaliza colonizada. Ecologia Politica y minería en America Latina. Buenos Aires: CLACSO, 2018.

FERNANDES, F.; ALAMINO, R.; ARAÚJO, E. Recursos Minerais e Comunidade: Impactos humanos. Socioambientais e econômicos. Rio de Janeiro, CETEM, 2014.

GORENDER, Jacob. O escravismo colonial. São Paulo. Expressão Popular, 2016. A escravidão reabilitada. São Paulo. Expressão Popular, 2016.

GREYL, L. Pascua Lama Mine, Argentin. In: Environmental Justice Atlas. Disponível em http://ejatlas.org/conflict/pascua-lama-mine-argentina. Acesso 29/09/2018.

GRÜNER, E. La obscuridad y las luces. Capitalismo, cultura y revolución. Buenos 
Direito, devir negro e conflito ecológico distributivo

Aires, EDHASA, 2010.

KEMP, D.; OWEN, J.; GOTZMANN, N.; BOND, C. Just Relations and Company Community Conflict in Mining. In: Journal of Business Ethics. 101: 93-109 Springer 2010.

MARTINEZ-ALIER, J. Mining conflicts, environmental justice, and valuation. In: Journal of Hazardous Materials n.86, 2001, pp. 153-170.

MARTINEZ-ALIER, J. The Environmentalism of the Poor: A Study of Ecological Conflicts and Valuation. Cheltenham, Edward Elgar, 2002.

MARTINEZ-ALIER, J. et al. (2010), Social metabolism, ecological distribution conflicts, and valuation languages. In: Ecological Economics Volume 70, Issue 2, p. 153-158.

MARTINEZ-ALIER, J. et al. (2011), Between science and activism: learning and teaching ecological economics with environmental justice organizations. In: Local Environment: The International Journal of Justice and Sustainability, Volume 16, Issue 1, 2011, p. 17-36.

MBEMBE, A. Crítica da Razão Negra. Lisboa, Antígona, 2014.

PÉREZ CEBADA, J. D. Tierra devastada. Historia de la contaminación minera, Madrid, Síntesis. 2014.

RICOEUR, Paul. A memória, a história, o esquecimento. Campinas: Editora Unicamp, 2007.

Tempo e Narrativa. Campinas: Ed. Papirus, 1994.

SAES, Décio Azevedo Marques de. O lugar da noção de sujeito na sociedade capitalista. Lutas Sociais, São Paulo, n.29, p.09-20, jul./dez. 2012. Disponível em http://www4.pucsp.br/neils/downloads/neils-revista-29-port/decio-azevedomarques.pdf. Acesso em 09/09/2018.

SAUER, Sergio. Terra no século XXI: Desafios e perspectivas da questão agrária Retratos de assentamentos. v.19, n.2, 2016.

SCHWARCZ, L.M. Nem preto nem branco, muito pelo contrário. Cor e raça na sociedade brasileira. São Paulo, Claro Enigma, 2012.

SERRA, O. Os Olhos Negros do Brasil. Salvador: EDUFBA, 2014.

SOTO FERNÁNDEZ, D. et all. La protesta campesina como protesta ambiental. Siglos XVIII-XX". In: História Agraria, 42, agosto, pp. 31-55. 2007.

SZASZ, A. EcoPopulism: Toxic Waste and the Movement for Environmental Justice, Minneapolis, University of Minnesota Press, 1994. 
TARREGA, Maria Cristina Vidotte Blanco. A construção narrativa do conceito de sujeito de direito e justiça. Revista da Faculdade de Direito da UFG, 35, 2012.

Ressignificação do Quilombo pelo Resgate dos Rastros no Constitucionalismo Democrático Latinoamericano. In SANTOS, Boaventura de Souza. e CUNHA, Teresa. Anais do Colóquio Internacional Epistemologias do Sul. Coimbra. 2015.

TEMPER, L.; Bene, D.; Martinez-Alier, J. Mapping the frontiers and front lines of global environmental justice: the EJAtlas. In: Journal of Political Ecology, 2015, 22: 255-278.

VISO, N.; Ramiro, P.; Bustelo, M. Conflictos socioecológicos: retos y perspectivas, Madrid, Centro de Investigación para la Paz (CIP-Ecosocial), 2012.

Artigo recebido em 16 de dezembro de 2018 e aceito em 28 de dezembro de 2018

1 O conteúdo dessa seção sobre afrodescendentes integrou um artigo intitulado Os Afrodescendentes no Constitucionalismo Democrático Latino-americano, escrito para ser publicado pelo Ministério Público da União. São informações consideradas relevantes para mostrar o estado da regulamentação legal e necessárias ao desenvolvimento das ideias, razão pela qual foram repetidas. 